Recebido em: 03/06/2020. Aprovado em: 15/04/2021. Publicado em: 20/08/2021

Processo de Avaliação: Double Blind Review - SEER/OJS

e-ISSN: 2359-5876

https://doi.org/10.48075/comsus.v8i1.25137

\title{
Avaliação das dificuldades e o conhecimento do produtor rural referente aos dejetos suínos
}

\section{Evaluation of difficulties and the knowledge of the rural producer regarding swine manure}

\author{
Luana do Pilar Machado ${ }^{1}$ \\ Emerson Lazzarotto ${ }^{2}$ \\ Rodrigo Pastl Pontes ${ }^{3}$
}

\section{Resumo}

O presente trabalho teve como objetivo avaliar o conhecimento técnico dos produtores rurais com relação ao manejo dos dejetos provenientes das atividades de suinocultura, bem como as dificuldades inerentes do processo. Para isso, foram realizadas visitas em 20 propriedades rurais com produção de suínos (até $3000 \mathrm{cb}$ ) e aplicado um formulário com perguntas objetivas. Após o tratamento dos dados coletados e a realização de uma análise de variância, concluiu-se que a tecnologia de tratamento dos dejetos utilizada, independe do número de suínos da propriedade. Além disso, foi constatado que os produtores rurais não possuem informações suficientes acerca da destinação mais adequada dos dejetos suínos e que ferramentas de baixo custo podem auxiliar nessa tomada de decisão, além de proporcionar maior segurança para o produtor e facilitar o manejo no processo de produção.

Palavras-chave: Produtor rural; Dejetos suínos; Tomada de decisão.

\begin{abstract}
The present study had as objective to evaluate the technical knowledge of the rural producers in relation to the handling of the manure originating from the swine farming activities, as well as the inherent difficulties of the process. For this, visits were made to 20 rural properties with swine production (up to $3000 \mathrm{cb}$ ) and a form with objective questions was applied. After processing the collected data and conducting an analysis of variance, it was concluded that the technology for processing the collected data does not depend on the number of swine on the property. In addition, it was found that rural producers do not have enough information on the most appropriate destination of pig manure and that low-cost tools can assist in this decision-making, in addition to providing greater security for the producer and facilitating management in the production process.
\end{abstract}

Keywords: Rural producer; Swine manure; Decision making.

Cite as: (APA Machado, L. P., Lazzarotto, E., Pontes, R. P (2021). Avaliação das dificuldades e o conhecimento do produtor rural referente aos dejetos suínos. Revista Competitividade e Sustentabilidade, 8(1), $133-142$.

\footnotetext{
${ }^{1}$ Universidade do Oeste do Paraná - UNIOESTE. Brasil. E-mail: mpluana@hotmail.com

2 Universidade do Oeste do Paraná - UNIOESTE. Brasil. E-mail: emerson.lazzarotto@unioeste.br

${ }^{3}$ Instituto Fraunhofer. Alemanha. E-mail: rpastl@gmail.com
} 


\section{Introdução}

Atualmente, considerando que o Brasil é um dos principais países no setor agroindustrial, torna-se necessário a preocupação com o tratamento dos resíduos gerados no processo de criação dos animais e a conciliação entre o desenvolvimento do setor e a sustentabilidade (Santos, 2014).

A produção de carne suína vem apresentando uma significativa expansão, em razão do aumento da demanda nacional e internacional. A suinocultura tornou-se uma das áreas de mercado mais atraentes para se investir no Brasil, devido à sua produtividade e rentabilidade (Melz \& Gastardelo, 2014). Num futuro próximo, a suinocultura será tão importante para a balança comercial do país quanto são hoje o frango e a carne bovina (Mauri, et al., 2017apud Lourenço, 2020).

A suinocultura representa uma atividade de grande potencial poluidor, devido à composição química dos dejetos, principalmente na criação em confinamento (Dos Santos \& Da Silva, 2019). Neste contexto, um ponto de alta relevância diz respeito à destinação incorreta dos dejetos produzidos pela criação de suínos, que tem causado grandes problemas ambientais.

A correta destinação dos dejetos provenientes da suinocultura, gerados nas propriedades rurais, é crucial para a sustentabilidade da atividade em questão. $O$ alto potencial poluidor dos efluentes gerados na criação de suínos é um tema de alta relevância do ponto de vista socioambiental, por isso a busca pela mitigação dos impactos inerentes ao negócio é crescente. Neste contexto, este artigo propõe avaliar as dificuldades e o conhecimento do produtor rural referente aos dejetos suínos, possibilitando maior exatidão na destinação dos dejetos suínos, facilitando o manejo da atividade e minimizando os impactos citados.

\section{Materiais e métodos}

A pesquisa foi desenvolvida na região oeste do Paraná, em granjas de suínos de pequeno porte (até 3.000 suínos). Para realizar o levantamento de informações referente aos dejetos suínos, realizaram-se visitas em 20 propriedades rurais que foram selecionadas de forma aleatória dentro de um conjunto composto por 300 propriedades. As visitas foram realizadas ao longo de uma semana, considerando a distância e disponibilidade das propriedades rurais (Figura 1). 
Machado, L. P., Lazzarotto, E., Pontes, R. P (2021). Avaliação das dificuldades e o conhecimento do produtor rural referente aos dejetos suínos.

Figura 1: Fotos de algumas propriedades visitadas. (a) Propriedade 9; (b) Propriedade 5; (c) Propriedade 12; (d) Propriedade 2.

(a)

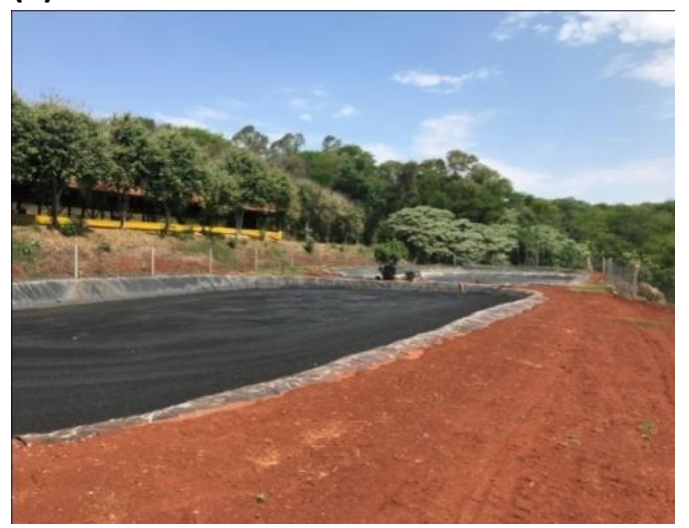

(c)

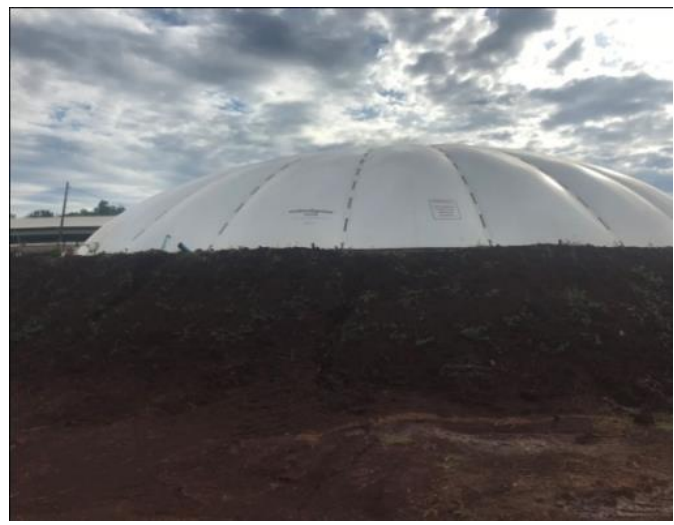

(b)

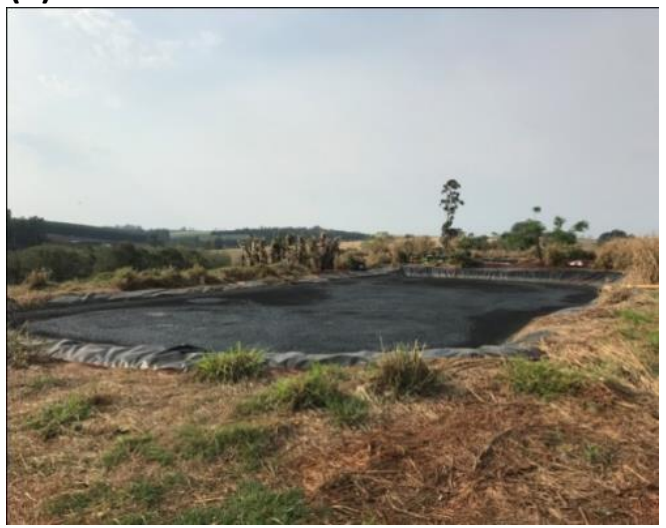

(d)

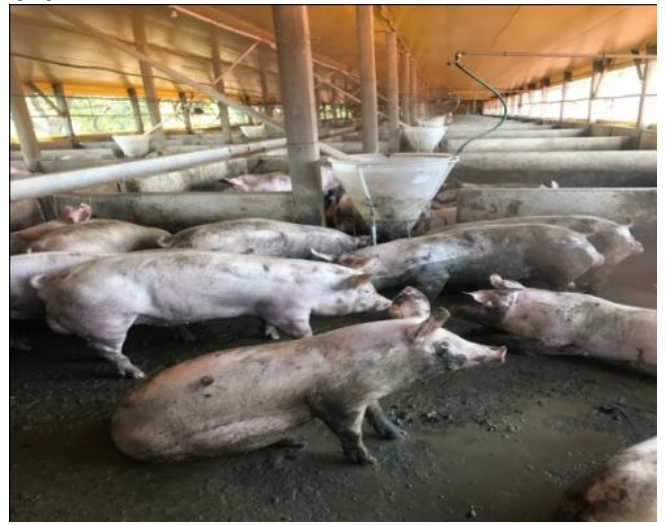

Fonte: Autor (2020).

Para a realização do trabalho, optou-se pela elaboração de um formulário composto por perguntas objetivas, a fim de verificar quais as necessidades e dificuldades dos pequenos produtores relacionadas ao tratamento dos dejetos suínos. O formulário da Figura 2, foi elaborado juntamente com as equipes técnicas do CIBiogás levando em conta os objetivos da pesquisa. O ClBiogás denominado Centro Internacional de Energias Renováveis,tem sido referência em desenvolvimento de pesquisas envolvendo o biogás e produtores de suínos. 0 formulário foi aplicado durante as visitas nas propriedades. 
Machado, L. P., Lazzarotto, E., Pontes, R. P (2021). Avaliação das dificuldades e o conhecimento do produtor rural referente aos dejetos suínos.

Figura 2: Formulário Coleta de Dados

\section{FORMULÁRIO COLETA DE DADOS}

DADOS PROPRIEDADE

1. Nome da propriedade/proprietário (Contato)

2. Cidade

3. Tamanho da granja?

4. Qual o sistema da propriedade? (Familiar, cooperativa, associação)

5. Possui funcionários? Quantos?

6. Possui corpo hídrico próximo?

7. Possui rede de esgoto e de água?

DADOS DEETOS

8. Volume diário de substrato $\left(\mathrm{m}^{3}\right)$

9. Possui biodigestor?

- Se não, possui tratamento dos dejetos?

Fonte: Autor (2020).

Todas as propriedades visitadas possuíam criação de suínos em fase de terminação e tinham um sistema familiar de produção. Nas visitas realizadas, observou-se tais características: posicionamento geográfico (latitude e longitude), quantidade de suínos, forma de armazenamento dos dejetos suínos (e/ou tratamento), destinação dos dejetos, origem da água da propriedade e proximidade de rio ou nascente.

Após a aplicação do formulário, realizou-se a tabulação dos dados para analisar possíveis correlações entre as propriedades.

\section{Resultados}

Após a coleta e análise dos dados referentes às 20 propriedades rurais, observou-se que este grupo dispõe no total de 26.560 mil suínos, produzindo diariamente $318,9 \mathrm{~m}^{3} / \mathrm{dia}$ de dejetos. As informações detalhadas estão na Tabela 1. 
Machado, L. P., Lazzarotto, E., Pontes, R. P (2021). Avaliação das dificuldades e o conhecimento do produtor rural referente aos dejetos suínos.

Tabela 1: Informações dos produtores de suínos

\begin{tabular}{|c|c|c|c|c|c|c|}
\hline $\begin{array}{l}\text { Granja/ } \\
\text { Produtor }\end{array}$ & Município & Plantel Suínos & $\begin{array}{c}\text { Volume de } \\
\text { dejetos } \\
\text { (m } \mathrm{m}^{3} / \text { dia) }\end{array}$ & $\begin{array}{c}\text { Rede de } \\
\text { Esgoto }\end{array}$ & $\begin{array}{l}\text { Corpo } \\
\text { Hídrico }\end{array}$ & $\begin{array}{c}\text { Possui } \\
\text { Biodigestor }\end{array}$ \\
\hline 1 & Nova Aurora - PR & 1600 & 19,2 & Não & Sim & Não \\
\hline 2 & Cafelândia - PR & 600 & 7,2 & Não & Sim & Não \\
\hline 3 & Cafelândia - PR & 1800 & 21,6 & Não & Sim & Não \\
\hline 4 & Penha - PR & 1200 & 14,4 & Não & Sim & Não \\
\hline 5 & Cafelândia - PR & 1200 & 14,4 & Não & Sim & Não \\
\hline 6 & Cafelândia - PR & 2200 & 26,4 & Não & Sim & Não \\
\hline 7 & Nova Aurora - PR & 1200 & 14,4 & Não & Sim & Não \\
\hline 8 & Cafelândia - PR & 1200 & 14,4 & Não & Sim & Não \\
\hline 9 & Penha - PR & 1800 & 21,6 & Não & Não & Não \\
\hline 10 & Cafelândia - PR & 1800 & 21,6 & Não & Sim & Não \\
\hline 11 & Penha - PR & 1800 & 21,6 & Não & Sim & Não \\
\hline 12 & Entre Rios - PR & 1700 & 20,4 & Não & Sim & Sim \\
\hline 13 & Entre Rios - PR & 1500 & 18 & Não & Sim & Sim \\
\hline 14 & Entre Rios - PR & 1500 & 18 & Não & Sim & Sim \\
\hline 15 & Entre Rios - PR & 1800 & 21,6 & Não & Sim & Sim \\
\hline 16 & Entre Rios - PR & 1250 & 15 & Não & Sim & Sim \\
\hline 17 & $\begin{array}{c}\text { Marechal C. Rondon } \\
\text { - PR }\end{array}$ & 560 & 6,72 & Não & Sim & Sim \\
\hline 18 & $\begin{array}{c}\text { Marechal C. Rondon } \\
\text { - PR }\end{array}$ & 650 & 7,8 & Não & Não & Sim \\
\hline 19 & $\begin{array}{c}\text { Marechal C. Rondon } \\
\text { - PR } \\
\end{array}$ & 550 & 6,6 & Não & Sim & Sim \\
\hline 20 & $\begin{array}{c}\text { Marechal C. Rondon } \\
\text { - PR }\end{array}$ & 650 & 7,8 & Não & Sim & Sim \\
\hline \multicolumn{2}{|r|}{ TOTAL } & 26.560 & 318,72 & & & \\
\hline
\end{tabular}

A Tabela 1 apresenta os dados referentes à presença de rede de esgoto e corpo hídrico nas propriedades visitadas. Da amostra estudada, nenhuma possui rede de esgoto e o lançamento dos dejetos domésticos é realizado em covas rasas. Apenas duas propriedades não possuíam corpo hídrico próximo.

\subsection{Discussões dos resultados}

A Figura 3 apresenta o percentual da tecnologia de tratamento da amostra estudada. Da sua análise é possível notar que, na amostra disponível de produtores, $45 \%$ possuem biodigestores implantados nas propriedades, os demais 55\% utilizam esterqueiras para 0 tratamento dos dejetos. Sabe-se que a utilização das esterqueiras intensifica o risco da degradação ambiental, uma vez que esses dejetos são utilizados em lavouras, muitas vezes acima do limite permitido, causando poluição do solo. Observa-se que a destinação inadequada desses dejetos é um dos grandes problemas nas áreas rurais e agrava os impactos ambientais.

A impermeabilização das esterqueiras precisa ser realizada para evitar infiltrações que possam contaminar as fontes de água e o solo. Devem ainda, operar com uma folga volumétrica de $20 \%$ de sua capacidade como medida de segurança (De Moraes, 2017).

Figura 3: Percentual da Tecnologia de Tratamento na amostra de Produtores. 
Machado, L. P., Lazzarotto, E., Pontes, R. P (2021). Avaliação das dificuldades e o conhecimento do produtor rural referente aos dejetos suínos.

\section{Existem mais esterqueiras do que biodigestores em Pequenas Propriedades}

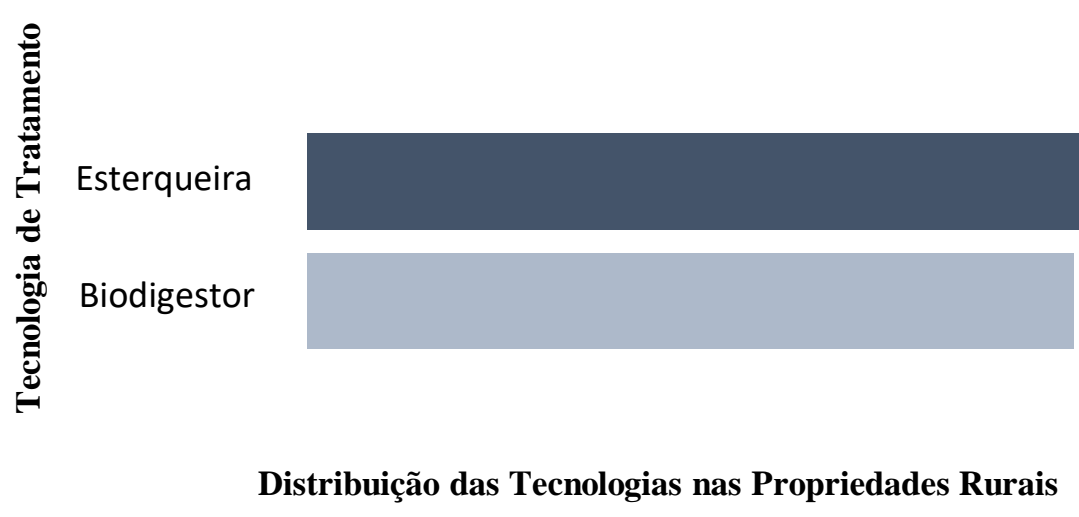

Fonte: Autor, (2020).

Na Figura 4 é possível visualizar a localização das propriedades. Observa-se que os produtores de pequeno porte que possuem biodigestores implantados estão concentrados na mesma região, justamente onde há a presença dos condomínios de Agroenergia Ajuricaba e Entre Rios. Estes são modelos de negócios criados com o intuito de aproveitamento energético de biogás originado da biomassa de suínos. O condomínio de Agroenergia Ajuricaba teve como parceiros no projeto a Itaipu Binacional, a prefeitura de Marechal Cândido Rondon, ClBiogás e Embrapa (Itaipu, 2016). O projeto de Entre Rios do Oeste contou com a parceria da prefeitura do município, CIBiogás, Copel e Fundação Parque Tecnológico de Itaipu (Entre Rios, 2019). 
Machado, L. P., Lazzarotto, E., Pontes, R. P (2021). Avaliação das dificuldades e o conhecimento do produtor rural referente aos dejetos suínos.

Figura 4: Localização das propriedades

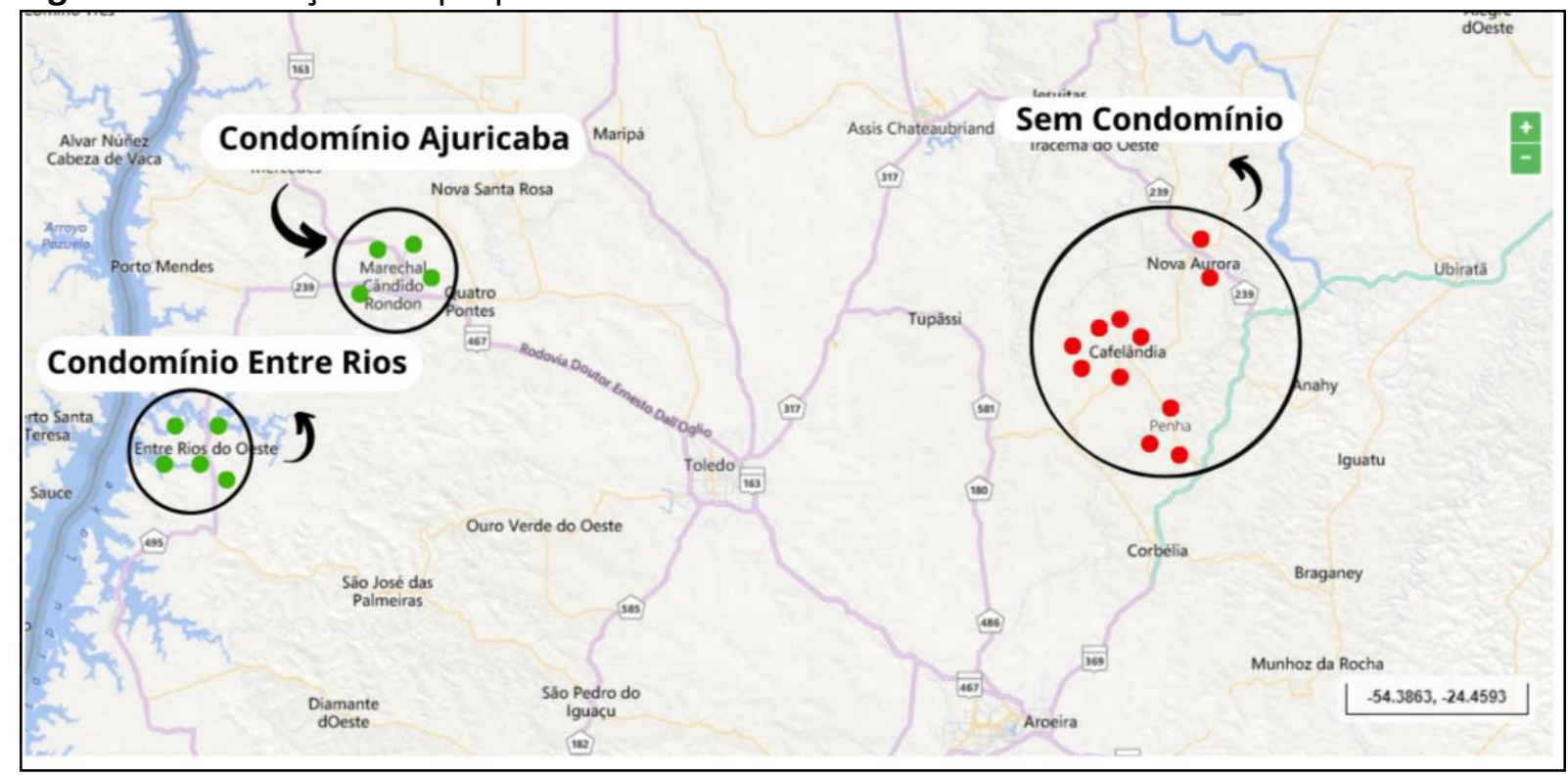

Fonte: BiogasMap, (2019).

A Figura 5 correlaciona a tecnologia de tratamento utilizada com a quantidade de suínos da propriedade.

Figura 5: Plantel de Suínos e Tipo de Tratamento

\section{Diagrama de Dispersão por Tratamento}

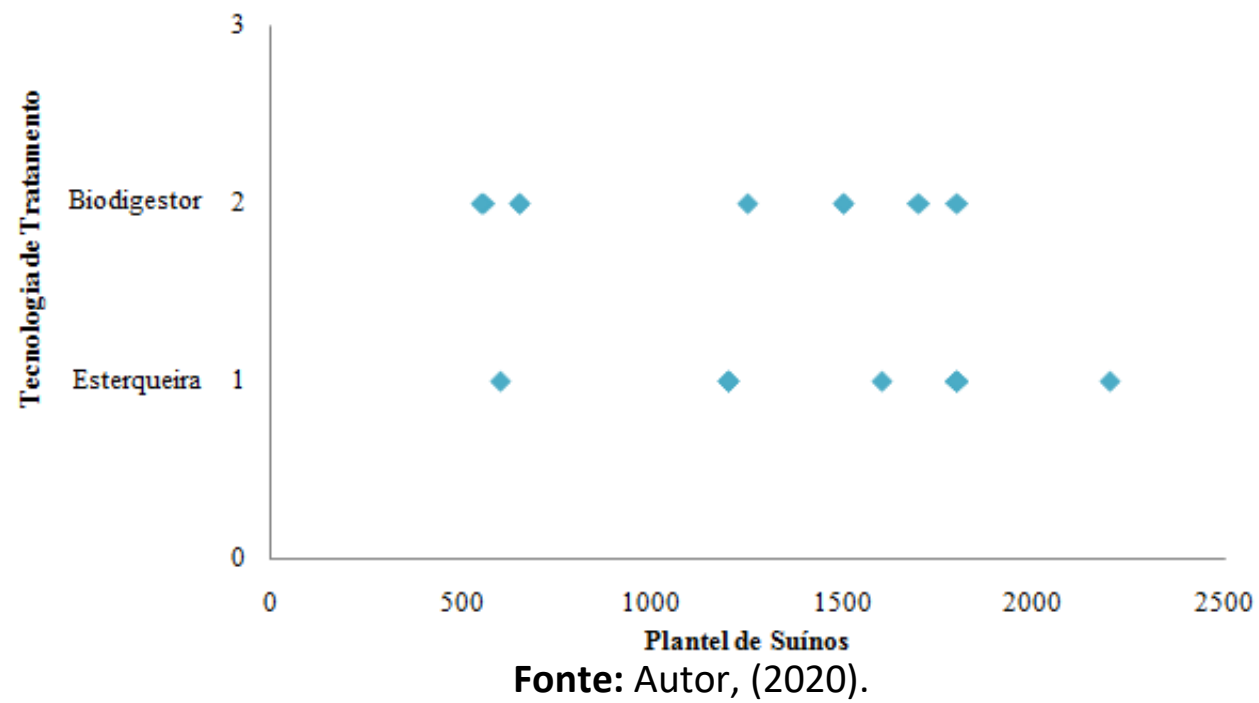

Tabela 2: ANOVA da Tecnologia de Tratamento e o Plantel de Suínos

\begin{tabular}{c|c|c|c|c|c}
\hline $\begin{array}{c}\text { Fonte de } \\
\text { Variabilidade }\end{array}$ & $\begin{array}{c}\text { Soma dos } \\
\text { Quadrados }\end{array}$ & $\begin{array}{c}\text { Graus de } \\
\text { Liberdade }\end{array}$ & Média & Razão - F & p-valor \\
\hline Entre Grupos & 648740, & 1 & 648740, & 2,77 & 0,1133 \\
\hline Dentro dos Grupos & $4,21318 \mathrm{E} 6$ & 18 & 234066, & & \\
\hline Total (Corr.) & $4,86192 \mathrm{E} 6$ & 19 & & & \\
\hline
\end{tabular}

Fonte: Autor, (2020). 
A Tabela 2 apresenta a tabela ANOVA (de análise de variância), um procedimento estatístico que testa se as médias de duas ou mais populações são iguais ou diferentes, através de duas hipóteses: a hipótese nula e a alternativa ( $\mathrm{HO}$ e $\mathrm{H} 1$, respectivamente) (da Rocha \& Júnior, 2018). A hipótese nula Ho: de que a tecnologia de tratamento independe do número dos suínos e a alternativa $\mathrm{H}_{1}$ : de que a tecnologia de tratamento depende do número dos suínos.

A razão $F$ que neste caso foi 2,77 é a razão entre a estimativa (entre grupos) e a estimativa (dentro dos grupos). Se o valor $p$ do teste $F$ for maior ou igual a 0,05 , não há diferença estatisticamente significativa entre a média do plantel para os dois tratamentos, uso de biodigestores e esterqueiras, ao nível de $95 \%$ de confiança. Por meio da análise do gráfico e da Tabela ANOVA, observa-se que, na amostra estudada, o tipo de tecnologia de tratamento implantada independe do número de suínos.

Após a análise das informações, é possível constatar que, os produtores que possuem sistemas de biodigestão implantados, fazem parte de algum modelo de negócio que incentiva a utilização do biogás como fonte energética por meio da cooperação de várias partes. Segundo Ceretta, Reis, \& Rocha (2016) e Chesbrough \& Rosenbloom (2002), as principais funções de um modelo de negócios são: a) articular a proposição de valor, b) identificar um segmento de mercado, c) definir a estrutura da cadeia de valor, d) estimar estruturas de custos e margens projetadas, e) escrever a posição da empresa na rede de valor e, f) formular a estratégia competitiva da organização. Os modelos de negócio facilitam a implementação dos projetos, tornando-os viáveis economicamente.

Por outro lado, notou-se que as propriedades que não participam de projetos ou parcerias que incentivam o uso do biogás, fazem uso de esterqueiras para tratamento dos dejetos.

\section{Considerações finais}

Com a realização das visitas, observou-se que todos os produtores possuem algum sistema de tratamento adequado para os dejetos suínos. Sendo que, na amostra analisada, foram identificados dois métodos de tratamento, a esterqueira e o biodigestor. Dentre estes métodos, a utilização do biodigestor é mais indicada pois este armazena o metano no balão do equipamento e evita a liberação do gás poluente na atmosfera, além de possibilitar aplicações energéticas que podem representar renda extra.

Após a análise proposta por este trabalho, é possível evidenciar que há dificuldade, por parte dos pequenos produtores, em implantar biodigestores sem a participação em projetos de parceria ou modelos de negócio que incentivam a implementação de tal tecnologia e oferecem informações sobre o manejo mais adequado dos dejetos.

A afirmação supracitada se baseia no fato de que, todas as propriedades visitadas que possuem sistemas de tratamento com biodigestores realizaram sua implantação por meio de algum projeto de parceria ou modelo de negócio. Por outro lado, os demais produtores relataram que a utilização deste tipo de sistema de tratamento não apresenta viabilidade econômica interessante e o manejo dos dejetos é uma das desvantagens na produção dos suínos.

Durante a aplicação do formulário, verificou-se que os produtores não possuem informação suficiente acerca da destinação mais adequada dos dejetos suínos, podendo dificultar o manejo da produção e muitas vezes onerar as atividades dos pequenos produtores rurais. 
As informações obtidas nesta pesquisa, possibilitaram maior conhecimento ao produtor no que se refere à destinação dos dejetos suínos. Tal conhecimento pode proporcionar ao produtor assertividade no processo e auxiliar na tomada de decisão referente ao manejo dos dejetos, uma vez que existe a necessidade de destinação correta e a possibilidade de agregação de valor, corroborando assim, com a sustentabilidade da atividade de suinocultura.

Como sugestão de trabalhos futuros, recomenda-se realizar pesquisa sobre o desenvovilmento de ferramentas ou modelos de classificação que destaquem a melhor oção para a destinação dos dejetos suínos. Outra indicação, refere-se à análise de viabilidade ecônomica considerando a utilização dos dejetos suínos como matéria prima. Podendo ser utilizada como substrato na geração de energia.

Por fim, uma proposta de pesquisa futura diz respeito ao estudo da qualidade hídrica de afluentes próximos às propriedades rurais, onde seria mensurado o impacto ambiental da atividade de suinocultura.

\section{REFERÊNCIAS}

Ceretta, G. F., Reis, R. D., \& Rocha, C. A. (2016). Inovação e modelos de negócio: um estudo bibliométrico da produção científica na base web of science. Gestão \& Produção .

Chesbrough, H., \& Rosenbloom, S. R. (2002). The role of the business model in capturing value from innovation: evidence from Xerox Corporation's technology spin-off companies. Industrial and Corporate Change .

Da Rocha, K. R., \& Júnior, A. B. (2018). ANOVA medidas repetidas e seus pressupostos: análise passo a passo de um experimento. . Revista Eletrônica Perspectivas da Ciência e Tecnologia , 10-29.

De Moraes, E. R. (2017). Suinocultura e o Meio-ambiente. Revisão de Literatura. . REDVET Revista Eletrônica de Veterinária , 1-17.

Dos Santos, T. D., \& Da Silva, M. V. (2019). A suinocultura e os Impactos ao Meio Ambiente. Ciência e Tecnologia , 43-48.

Entre Rios. (05 de 10 de 2019). Projeto do biogás tem início em Entre Rios do Oeste. Fonte: Prefeitura de Entre Rios do Oeste:

http://entreriosdooeste.pr.gov.br/noticia/211/projeto-do-biogs-tem-inicio-em-entrerios-do-oeste

Itaipu. (05 de 10 de 2016). Projeto Pioneiro na Produção de Biogás Completa Sete Anos. Fonte: Itaipu Binacional: https://www.itaipu.gov.br/sala-de-imprensa/noticia/projetopioneiro-na-producao-de-biogas-completa-sete-anos

Lourenço, S. J. (15 de 01 de 2020). Histórico e Evolução do Agronegócio Brasileiro. Fonte: Sucesso no Campo: https://www.sucessonocampo.com.br/artigos/historico-eevolucao-do-agronegocio-brasileiro

Mauri, G. N., De Lima, J. G., Pozo, O. V., \& De Freitas, R. R. (2017). Startups no agronegócio brasileiro: uma revisão sobre as potencialidades do setor. Brazilian Journal of Production Engineering - BJPE , 107-121. 
Machado, L. P., Lazzarotto, E., Pontes, R. P (2021). Avaliação das dificuldades e o conhecimento do produtor rural referente aos dejetos suínos.

Melz, L. J., \& Gastardelo, T. A. (2014). A suinocultura industrial no mundo e no Brasil. Revista UNEMAT de Contabilidade, 72-92.

Santos, R. G. (10 de 03 de 2014). Agroindústria no Brasil: um olhar sobre indicadores de porte e expansão regional. Brasil em desenvolvimento: Estado, Planejamento e Políticas Públicas. Brasília, DF, Brasil. 